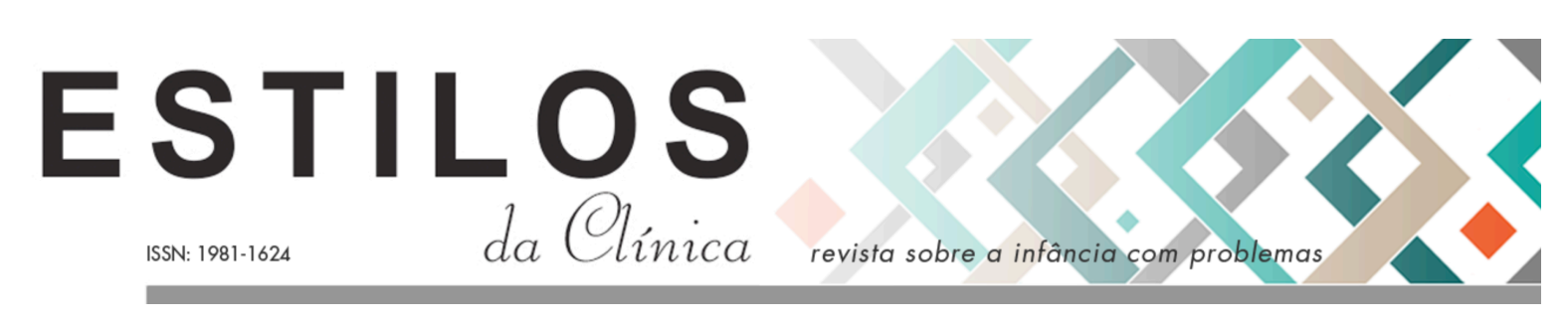

DOI: https://doi.org/10.11606/issn.1981-1624.v26i1 p17-28.

\title{
Dossiê
}

\section{Notas sobre o fazer de uma psicóloga escolar na pandemia}

\author{
Carolina Apolinário de Souza
}

\begin{abstract}
Resumo. Sabemos que o ato de educar é uma prática social discursiva, imergindo a criança na linguagem e a tornando capaz de fazer laço social. Entretanto, o ensino a distância (EAD) impôs-se como realidade atual. Como consequência, as restrições sociais e esse novo modo de estar na escola impactaram a saúde mental de alunos, de pais e de professores, e o psicólogo escolar foi convidado a ajudar na construção de formas possíveis de atravessamento do mal-estar. Este artigo, portanto, propõe reflexões acerca do meu trabalho como psicóloga escolar de orientação psicanalítica. Atuando em uma escola particular, durante uma pandemia que afastou os alunos da escola, defendo que a escola seja um 'lugar de vida' (Kupfer, 2010), constituindo-se como palco de construção de sentidos para experiências prazerosas e desafiadoras.
\end{abstract}

Palavras chave: pandemia; mal-estar; psicólogo escolar.

\section{Notas sobre la actuación de un psicólogo escolar en la pandemia}

Resumen. Sabemos que el acto de educar es una práctica social discursiva, que sumerge el niño en el lenguaje y lo hace capaz de crear un vínculo social. Sin embargo, la educación a distancia (EAD) se ha convertido en una realidad actual. Como consecuencia, las restricciones sociales y esta nueva forma de estar en la escuela impactaron la salud mental de alumnos, padres y profesores y el psicólogo educativo fue invitado a ayudar en la construcción de posibles vías de traspaso del malestar. Este artículo, por lo tanto, propone reflexiones sobre mi trabajo como psicólogo de orientación psicoanalítica en una escuela. Actuando en una institución privada, durante una pandemia que sacó a los estudiantes de la escuela, defiendo que la escuela es un 'lugar de vida' (Kupfer, 2010), constituyéndose como un escenario para la construcción de significados para experiencias placenteras y desafiantes.

Palabras clave: pandemia; malestar; psicólogo educativo.

\section{Notes on the work of a school psychologist during the pandemic}

Abstract. It is already known that the act of educating is a social discursive practice, immersing the child in language and making them capable of stablishing social bonds. However, distance learning has become an imposed reality. As a consequence, social restrictions and this new way of being at school impacted the mental health of

*Psicóloga escolar. Doutora em Estudos da Linguagem pela Pontifícia Universidade Católica do Rio de Janeiro, Rio de Janeiro, RJ, Brasil. E-mail: carolinaapolinariopsi@gmail.com 
students, parents and teachers and the school psychologist was invited to support the construction of possible ways of dealing with hardship. This article, therefore, proposes reflections on my work as a school psychologist of psychoanalytical approach. Acting in a private school, during a pandemic that removed students from school, I claim that the school is a 'life place' (Kupfer, 2010), a stage where subjects can construct meanings for pleasant and challenging experiences.

Keywords: pandemic; hardship; school psychologist.

\section{Notes sur l'action d'un psychologue scolaire dans la pandémie}

Résumé. On sait que l'acte d'éduquer est une pratique discursive sociale que introduit l'enfant dans le langage et le rend capable de faire un lien social. Néanmoins l'enseignement à distance est devenu une réalité nécessaire. En conséquence les restrictions sociales et une nouvelle façon d'être à l'école(EAD) ont eu un impact sur la santé mentale des élèves, des parents et des enseignants et le psychologue scolaire a été invité dans la pandémie à aider le sujet à construire des voies possibles pour traverser le malaise. Cet article propose des réflexions sur mon travail comme psychologue scolaire d'orientation psychanalytique dans une école privée de Rio de Janeiro lors d'une pandémie qui a éloigné des milliers d'élèves de l'école. Je soutiens avec Kupfer (2010) que l'école est un «lieu de vie» car elle constitue une étape pour la construction de sens d'expériences agréables et désagréables.

Mots clés: pandémie; malaise; psychologue scolaire.

Já estávamos advertidos, desde o texto freudiano "O mal-estar na civilização" (1930/1996), sobre o incômodo que a tarefa de viver em sociedade nos causa. No entanto, não estávamos preparados para a devastação física, psíquica e social ${ }_{2}$ causada mundialmente por este inimigo invisível denominado Sars-CoV-2.

Freud apontava ali que a origem do sofrimento humano residiria em três fontes: a relação com o outro, a perenidade de nosso corpo e os perigos do mundo externo. A recomendação de isolamento social, devido ao alto risco de contaminação, impôs a nós restrições em relação ao contato com o outro, à nossa liberdade de ir e vir, à nossa privacidade, aos nossos planos e expectativas. As restrições trazidas pelo vírus impactaram todas as faixas etárias, a partir de diferentes lugares subjetivos. O impacto social, econômico, ético e psíquico é notório e nos convida a olhar para a instituição escolar e para a sua indiscutível importância. Num aspecto macro, a escola situa o sujeito no contexto econômico, político e social da sociedade onde vive, ao mesmo tempo que nos convoca a olhar para a singularidade de cada um. O recorte que aqui trago refere-se à minha prática institucional na rede de ensino privada no RJ. Os efeitos que tangem ao impacto do Covid-19 no ensino público são igualmente importantes e penso que devem ser trazidos a partir da experiência de dentro dessas instituições, que foram, em sua maioria, excluídas da possibilidade de ensino a distância.

A partir dos estudos de alguns filósofos da educação, como Austin (1962) e Bondía (2002), proponho pensar a educação a partir do par experiência/sentido. Bondía (2002) marca que as palavras produzem sentido, criam realidades e podem funcionar como mecanismos de subjetivação.

Nomear o que fazemos em educação ou em qualquer outro espaço como práxis reflexiva ou como experiência dotada de sentido não é somente uma questão terminológica. Para Bondía (2002), “a experiência é o que nos passa, o que nos acontece, o que nos toca. Não o que se passa, não o que acontece, ou o que toca. A cada dia se passam muitas coisas, porém, ao mesmo tempo, quase nada nos acontece”. Minha intenção como profissional é convidar professores, 
pais e alunos a trabalharem para entender e para colocar em palavras, na medida do possível, o que lhes acontece como sujeitos na escola. Este texto é justamente uma tentativa de nomear algumas impressões sobre um fazer, orientado pela psicanálise, na instituição escolar, neste momento tão delicado e tão devastador. Como não posso falar sobre a experiência de cada um, resta-me escutar e ser tocada pelo meu fazer no espaço escolar, colocando algumas de minhas impressões como psicóloga institucional em meio a um período cultural que lança luz sobre a saúde mental dos alunos ${ }^{1}$.

Minha experiência institucional se faz na troca com alunos, pais, professores e gestores da Educação infantil até o início do Fundamental II. Testemunhei, como profissional, que as mudanças e as dificuldades que o ensino remoto impôs foram profundas para todas as camadas da comunidade escolar. A partir de minha inserção institucional, construí alguns entendimentos diante do mal-estar dos alunos, encaminhados ao Setor de Psicologia da escola, durante a pandemia que levou à interrupção das aulas presenciais em março de 2020 e ao início das aulas a distância no mesmo mês.

\section{Qual a função do psicólogo escolar?}

O escopo de atuação do psicólogo na instituição escolar ainda é um tema de discussão e de reflexão entre profissionais da educação. Como aborda Martinez (2010), no que se refere à função do profissional da psicologia, a equipe pedagógica, os próprios alunos e os pais parecem ter dúvidas sobre sua inserção na equipe escolar. Em que situações o psicólogo deve intervir? Qual a especificidade do seu trabalho em relação ao desempenhado pelos outros profissionais da escola? Quais situações requerem uma prática individual do psicólogo e quais demandam uma parceria de trabalho com a equipe?

A partir do legado de Freud, Lacan formula que a ética na qual se baseia a Psicanálise é a ética do bem-dizer. Ou seja, as atuações, os sintomas e os não-ditos que marcam o sujeito podem, a partir de uma escuta, servir para que ele construa outros sentidos e para que ressignifique experiências, passando a entender mais sobre seus processos inconscientes.

Segundo alguns autores brasileiros dedicados à investigação da Psicologia Educacional contemporânea, tais como Kupfer, Lajonquière e Aquino ${ }^{2}$, a função do psicólogo na escola não consiste em dizer aos professores como devem proceder em sala de aula, mas promover reflexões junto à equipe pedagógica, aos pais e aos alunos.

Kupfer (2013) aponta que o trabalho do psicólogo escolar ou do orientador educacional não se pratica somente na sala de aula, mas também em seu entorno. A autora comenta que esses profissionais são convocados pelas escolas para resolver desde problemas de indisciplina e de socialização até os de planejamento geral da escola, passando pelos pedidos de realização de encaminhamentos das 'crianças-problema' para psicólogos clínicos e para psicanalistas.

Cabe-nos lembrar que, na infância, muito frequentemente,- a queixa que sinaliza a existência de um sintoma é trazida pelos pais ou pelos professores diante da observação do aluno no

\footnotetext{
Com o advento da pandemia, organizações mundiais como a OMS, a UNICEF e a UNESCO dedicaram-se à elaboração de pesquisas e de documentos com foco na saúde mental de crianças e de jovens para orientar escolas, alunos e pais.

2 Os autores Kupfer (1982, 1989, 1999, 2004, 2005, 2010, 2013), Lajonquiere (1998, 2006) e Aquino (1996, 1997, 1998, 1999, 2010, 2013) têm se dedicado ao estudo das dissonâncias e das ressonâncias entre a Psicanálise e a Educação.
} 
âmbito familiar ou escolar, e não pelo próprio sujeito. Assim, a criança, muitas vezes ${ }_{2}$ precisa que seu mal-estar seja reconhecido por um adulto antes que possa começar a problematizá-lo. Ou seja, o psicólogo é convocado a atuar no espaço escolar, com base num mal-estar relatado pela equipe pedagógica, ou por seus pais. No entanto, sabemos que há diferentes tipos de intervenções possíveis dentro desta prática.

Kupfer (2013) indica que, quando atravessados pela psicanálise, alguns psicólogos têm concebido seu papel de modo diferente daquele que as escolas lhes designam, entendendo que a instituição escolar está sujeita às leis de funcionamento da linguagem, que valoriza os discursos dos sujeitos. Logo, podemos ler os discursos que ali se desenrolam da mesma maneira como se leem os discursos de um sujeito em análise. A autora esclarece que não se trata de psicanalisar as pessoas da instituição, mas de aplicar as regras de funcionamento da linguagem à instituição como um todo e de escutar o sujeito de um lugar que busca fazer circular a palavra, quer seja entre alunos, quer seja entre pais, professores ou gestores.

A psicanálise dá especial importância ao termo "escutar", em detrimento do "ouvir". Essa sutil diferença é bastante relevante. Se tudo vai bem com nosso aparelho auditivo, podemos ouvir. No entanto, escutar requer habilidades mais sutis. Para escutar, é preciso ter atenção, curiosidade, espanto e admiração com as pessoas e com o que acontece fora de nós. Dunker e Thebas (2019) ressaltam que a escuta começa por uma espécie de renúncia ao exercício do poder. Os lugares constituídos ou sentidos antecipados são suspensos e apenas as palavras pronunciadas ganham poder, independentemente de quem as pronunciam. Nesse sentido, a condição da escuta residiria na vulnerabilidade que estabelece uma conexão. Os autores descrevem quatro modalidades de escuta, das quais elejo uma para falar sobre minha experiência com a escuta escolar: a hospitalidade. Trata-se de acolher o que o outro diz em sua linguagem e em seu tempo próprio. "Hospedar é acolher, receber, sentir satisfação em dar guarida ao viajante exausto ou ao guerreiro ferido" (Dunker \& Thebas, 2019).

Acredito que, para a ética dessa psicologia escolar a qual me refiro, o entendimento sobre o mal-estar deva ser coconstruído com a equipe pedagógica, para que o sujeito crie formas de manejo mais saudáveis e mais autônomas. Esses entendimentos podem ter início por meio do oferecimento, pelo psicólogo, de um espaço de escuta - um espaço seguro de reflexão e sem julgamentos, ao qual o sujeito pode acessar e retornar.

$\mathrm{O}$ verbo hospedar inclui o conceito de interdisciplinaridade. Investigar o mal-estar na escola significa dar lugar de escuta ao sujeito e a todos que se relacionam com ele. Proponho que, no campo escolar, o termo interdisciplinaridade ganhe uma acepção mais ampla, já que a escuta e o manejo do mal-estar devem incluir não só psicólogo e o aluno, mas também a família, os profissionais da escola e os profissionais externos que oferecem suporte ao aluno (psicólogos, neuropediatras, psiquiatras, psicopedagogos, fonoaudiólogos, terapeutas ocupacionais etc). É a partir desse lugar hospedeiro da escola que o aluno pode ir tecendo, aos poucos, seu lugar no mundo.

Citando Kupfer, entendo que, "quando há circulação de discursos, as pessoas podem se implicar em seu fazer, podem participar dele ativamente, podem se responsabilizar por aquilo que fazem ou dizem. Mudam ativamente os discursos, assim como são por eles mudadas, de modo permanente" (Kupfer, 2013, p.137).

Diversos trabalhos de Kupfer $(2004,2005,1999,2010)$ identificam a instituição escolar como importante referência de transmissão da cultura, apontando que algumas intervenções no campo escolar, ao tocar o ponto da relação do sujeito com o outro, podem realizar giros discursivos que modificariam a posição do sujeito frente a si e ao outro. Essa vivência e esse 
confronto com outras subjetividades, para além do conhecido núcleo familiar, podem ter em si efeitos terapêuticos.

O encontro com o outro, tão diferente e, ao mesmo tempo, semelhante, insere a criança, desde o início da escolarização, em uma série de desafios diários que envolvem autonomia, empatia, flexibilidade, negociação, tolerância ao ritmo do outro, paciência e cooperação. É na escola que a criança não só é apresentada pela primeira vez a conflitos com um outro fora de seu núcleo familiar, como também aprende a solucioná-los. Diz Freud (1930/1996, p. 101): “A substituição do poder do indivíduo pelo poder de uma comunidade constitui o passo decisivo da civilização". Pode-se, então, concluir que a escola é um local essencial nessa transformação do sujeito como ser social.

Freud (1914/1996) destaca que a saúde mental dos sujeitos reside em sua capacidade de amar e de trabalhar. O amor, obra de Eros, é responsável tanto pelos laços afetivos que sustentam o processo civilizatório quanto pelo erotismo. Freud (1914/1996) ainda pontua que é preciso amar para não adoecer. $\mathrm{O}$ trabalho é um importante fator para a manutenção do equilíbrio psíquico, pois está atrelado a outros destinos pulsionais, tais como a criação e a inserção social do sujeito. Em suma, o amor nos mantém investidos libidinalmente, enquanto o trabalho, além de nos manter investidos, nos garante um lugar social.

A meu ver, na infância, o trabalho enquanto responsabilidade social pode ser representado pelo que se dá no espaço escolar. Nesse espaço, as crianças produzem, erram, acertam, tentam novamente, são avaliadas e são reconhecidas por suas produções diariamente. É neste mesmo espaço que estabelecem relações de afeto com seus pares e com seus professores e, mais ainda, constituem-se narcisicamente. Vão descobrindo-se na relação com seus pares, com a estrutura formal do ensino e com o conhecimento em si. Tomando a proposta de Freud de atuação sobre a saúde mental, entendo que a capacidade de amar e de trabalhar que a criança exerce na escola está claramente ligada à expressão de sua subjetividade. Mas, como ficou, na pandemia, essa capacidade da criança de amar e de trabalhar ao ser atropelada pelo afastamento da escola presencial tal qual conhecíamos?

\section{Escola e laços sociais: efeitos do isolamento}

Já que não podemos extrair beleza da vida, busquemos ao menos extrair beleza de não poder extrair beleza da vida. Façamos da nossa falência uma vitória, uma coisa positiva e erguida, com colunas, majestade e aquiescência espiritual. Se a vida [não] nos deu mais do que uma cela de reclusão, façamos por ornamentá-la, ainda que mais não seja, com as sombras de nossos sonhos, desenhos e cores mistas esculpindo o nosso esquecimento sob a parada exterioridade dos muros. (Pessoa, 2006, p. 287)

A vulnerabilidade dos nossos corpos diante de um inimigo externo passou a nos privar da liberdade, do contato com a natureza e, ainda, do exercício de nossa atividade laboral. Além do medo da contaminação, o medo da crise financeira assombrou muitas famílias, trazendo impacto para as relações subjetivas no núcleo familiar.

$\mathrm{Na}$ leitura psicanalítica, a educação é entendida como um ato de cultura. $\mathrm{O}$ ato de educar é uma prática social discursiva, imergindo a criança na linguagem e a tornando capaz de dirigirse ao outro e de produzir discurso ou, em outras palavras, de fazer laço social. Voltolini (2011) pontua que o laço social é uma relação possível entre o sujeito e o Outro, marcada sempre por 
um desencontro constitutivo da linguagem: entre dois inconscientes, nunca poderá haver a compreensão total, algo sempre escapa. Contraditoriamente, é justamente o reconhecimento das diferenças, das disjunções e da incompletude que pode viabilizar um encontro. Na mesma via, a escola é entendida como "lugar de vida" (Kupfer, 2010), pois se constitui como palco de construção de sentidos para experiências prazerosas e desprazerosas. Lugar de várias travessias.

Lembremos que o sujeito do inconsciente é efeito do discurso social, ou seja, a interpretação que cada sujeito faz do mundo está embebida na cultura da qual faz parte. A situação social em que nos encontramos é uma pandemia que afetou diretamente os vínculos do sujeito. As crianças deixaram de ter outros espaços de interação e passaram a ficar enclausuradas e, ao mesmo tempo, muito mais próximas aos pais. Os espaços de pausa, de escansão e de privacidade passaram a ser mais raros e precisaram ser redescobertos no interior de cada núcleo familiar. Até os espaços de trabalho e de estudo misturaram-se nesse contexto. Há uma imersão familiar compulsória no que tange ao ensino a distância. Crianças que iniciavam o Fundamental I já alfabetizadas e começavam a construir seu espaço de autonomia e de separação veem-se novamente referidas à supervisão constante dos pais diante da tela escolar. Por outro lado, são justamente as telas que fazem função de janela para fora da "cela de reclusão", retomando a expressão de Pessoa. A única opção possível de conexão e de ensino pode, ao mesmo tempo, abrir caminho para o laço ou para um isolamento social.

A desconfiança, a ameaça permanente e o medo da morte afligiram crianças, jovens e adultos, mobilizando os sujeitos para atitudes generosas, cooperativas e altruístas, mas também mobilizaram a agressividade, o isolamento e o medo do contato (Rodriguez, 2020). Familiares mais idosos foram afastados do convívio com as crianças, que podem ser possíveis vetores. A morte que, até então, para muitas famílias, era um tema inominável, passou a aparecer no discurso dos pais de forma mais aberta, no intuito de implicar também as crianças em formas possíveis de lidar com um inimigo invisível. Lavar as mãos, praticar isolamento social e utilizar equipamentos de proteção individual são medidas de saúde pública e nossas únicas e precárias formas de tentar barrar a ameaça externa.

\section{Encontros e desencontros na escola}

Assim como um planeta gira em torno de um corpo central enquanto roda em torno de seu próprio eixo, assim também o indivíduo humano participa do curso de desenvolvimento da humanidade, ao mesmo tempo que persegue seu próprio caminho na vida." (Freud, 1930/1996, p. 143)

Kupfer e Gaviolli (2011) trazem uma imagem interessante para marcar o efeito da educação no sujeito, ressaltando que o ato de educar seria o meio pelo qual o social se "intromete na carne" da criança, transformando-a em linguagem (Kupfer \& Gaviolli, 2011). Os pais distinguem seus filhos com marcas de desejos e de ideais. Nessa direção, as autoras sublinham que $o$ ato educativo pode ser ampliado a todo ato de um adulto dirigido a uma criança com o sentido de favorecer o laço social e de filiar o aprendiz a uma tradição existencial.

As autoras defendem a ideia de que o trabalho com a criança-sujeito deve propiciar espaços de construção de subjetividade. Ou seja, tratar pode incluir o ato de educar, e educar pode incluir o ato de tratar. Sabemos que a escuta não é exclusividade do psicanalista, tendo se tornado peça fundamental para o educador. A proposta é de que o educador, ao escutar e ao acompanhar o aluno em sua busca por dizer sobre si e sobre suas dificuldades (ao invés de tamponar essa angústia condicionando-a a formas mais funcionais de comportamento que excluem a reflexão), 
também o está tratando. Educar é, portanto, oferecer recursos para que o sujeito possa lidar com a certeza da morte e do desamparo humano. É tecer com o aluno formas de lidar com a castração simbólica que nos impõe limites, desencontros e frustrações. Oferecer recursos implica colocarse disponível, caminhar a seu lado, propor perguntas e construir soluções para fazer face ao mal-estar. Ao disponibilizar-se como esse acompanhante, o educador estará também tratando o aluno, não no sentido médico da palavra que visa eliminar ou prevenir transtornos, mas na acepção de acompanhar as crianças em suas conquistas e em seus tropeços no enfrentamento do real ${ }^{3}$.

No meu trabalho, as trocas e as discussões com educadores e com gestores se fazem fundamentais, principalmente, no ensino a distância (EAD), onde dependo, em parte, da informação trazida por eles para agendar os atendimentos. Ao escutar pais e alunos, percebi que o sofrimento diante das restrições trazidas pelo vírus impôs-se como tema comum. O malestar com a perda do laço com os pares, o medo de contaminação e, em última instância, da morte, a perda da vivência em espaços já conquistados (atividades extracurriculares por exemplo), a dificuldade de organização e de engajamento frente a este novo formato de ensino e a perda da privacidade da vida escolar foram questões trazidas pelos alunos. O espaço de escuta oferecido por mim, como psicóloga escolar, tinha o desejo de fazer furo nesse confinamento, fazendo circular a palavra.

Retomando o texto do Mal-estar, Freud examina a relação do homem com a felicidade. Ele pontua que, na busca pela felicidade, demanda-se não só a felicidade como alvo final, mas também a evitação do desprazer e da frustração, em prol de sentimentos fragmentados de prazer. No entanto, Freud não deixa de indicar que a felicidade encontrada é sempre relativa e temporária, e é no dia a dia que o sujeito pode experimentá-la. É esperado, portanto, que os momentos de felicidade sejam intercalados com momentos de dificuldade e de perdas. Sob este prisma, a felicidade possível refere-se à capacidade libidinal de cada sujeito de construir formas próprias de modificar o mundo externo no sentido do que deseja, aceitando que o estado das coisas não é permanente. Mesmo com a aridez do cenário distópico da pandemia, percebi que a instituição escolar tentou se sustentar como fonte de esperança, apostando no ensino, nas trocas entre os membros de sua comunidade e no desejo de retorno ao espaço físico escolar num momento propício.

À medida que os alunos e os pais esboçavam suas dificuldades em concluir as atividades sem o auxílio do professor, os pais tentavam ocupar seu lugar de transmissão de saber e com expectativas difusas sobre a performance dos filhos. Conforme as semanas passavam, o malestar e as dissonâncias entre o ensino remoto e o ensino presencial iam se impondo. Se, no início, a instituição escolar tentou produzir repetições, preservando os hábitos do ensino presencial, gradualmente, foi-se percebendo que inúmeros ajustes pedagógicos precisavam ser feitos no sentido de garantir que a escola se sustentasse como lugar de encontros.

3 Refiro-me aqui ao conceito lacaniano de real. O real de Lacan não se assemelha ao real da ciência ou da realidade no uso do senso comum, e também não se restringe à realidade psíquica de Freud. Para Lacan, o real tem múltiplas faces, mas é sempre o impossível de ser simbolizado. A impossibilidade, o acontecimento e o trauma são suas principais características. Ele se impõe ao sujeito, acontece. Conforme nos esclarecem Zyzek e Daly: "Um trauma ou um ato é simplesmente o ponto em que o Real acontece, e isso é difícil de aceitar” (Zyzek \& Daly, 2006). 


\section{Cenas do mal-estar educacional}

No início da pandemia, a incerteza, o medo e a imprevisibilidade perpassavam todas as instâncias escolares. À medida em que foi se entendendo que a situação não se encerraria a curto prazo, passei a ser, como psicóloga educacional, acessada constantemente e incluída em discussões, junto aos gestores, sobre a saúde mental não só de alunos, como também dos professores.

Do ponto de vista do docente, a intensidade do trabalho remoto teve impacto em sua saúde física e psíquica. $\mathrm{O}$ aumento de horas de exposição às telas culminou num excesso de trabalho e numa dificuldade de impor limites à demanda dos alunos e dos pais. O professor, que trabalhava em horários específicos, passou a ser acessado ininterruptamente pelos chats usados no EAD. No caso de algumas instituições, os professores e os profissionais (como psicólogos e orientadores educacionais) eram encorajados a se comunicar com pais e com alunos por meio de seus dispositivos celulares ou de redes sociais privadas como Whatsapp. Dessa forma, os limites entre vida privada e vida profissional se entrecruzavam.

Uma pesquisa realizada por Nova Escola (https://novaescola.org.br/conteudo/19386/qual-ea-situacao-dos-professores-brasileiros-durante-a-pandemia, recuperado em 1 de julho, 2020) relata que muitos educadores tiveram a saúde mental afetada durante a pandemia do novo coronavírus. 8.121 docentes responderam à pesquisa denominada "A situação dos professores no Brasil durante a pandemia", realizada entre os dias 16 e 28 de maio de $2020.30 \%$ dos professores respondentes à pesquisa classificaram a experiência de ensino remoto como ruim ou péssima. O levantamento teve por objetivo mapear alguns cenários vivenciados pelos educadores brasileiros no ensino remoto. O agravamento de questões de saúde mental como estresse, insônia e ansiedade foi reportado pela maioria destes profissionais.

Tal como o mito do leito de Procusto ${ }^{4}$, a tendência inicial de muitas escolas foi transpor o conteúdo presencial para o EAD, inferindo que os pais pudessem, com facilidade, mediar essa aprendizagem. Do ponto de vista da transposição do ensino presencial para o ensino a distância, as adaptações nos conteúdos ensinados foram acontecendo vagarosamente.

Se a casa é o refúgio considerado mais seguro do ponto de vista físico, também pode causar estranhamento e desconforto do ponto de vista psíquico. Pensemos na relação da criança com a escola como um espaço para além do domínio familiar, e que lhe garantiria alguma privacidade, ainda que limitada. À medida que a escola transfere-se para a sala de estar de casa, muitas questões são trazidas à tona. Ao mesmo tempo que se familiarizam com cantos da casa outrora esquecidos ou desconhecidos, os pais passam também a assistir às aulas dos professores, para ajudar os filhos. Observei aqui dois efeitos possíveis. Alguns professores relataram sentirem-se vigiados e com sua espontaneidade tolhida nas aulas a partir desse olhar parental. Como outro lado da moeda, outros professores relataram uma maior valorização de seu trabalho, antes não acompanhado tão de perto.

O espaço da escola e das relações que ali se estabelecem passou a ser compartilhado com os pais. A relação dos filhos com o saber é assistida diariamente a uma distância quase inexistente.

4 O mito do leito de Procusto. Mito grego que narra a história d o personagem Procusto, um bandido impiedoso que possuía uma cama de ferro de seu exato tamanho. Seu passatempo era capturar viajantes e fazerem-nos deitar em sua cama. Caso eles fossem maiores, cortava-lhes as pernas. Caso fossem menores, esticava-os até caberem exatamente no leito. O mito é uma metáfora para a questão da intolerância, a tentativa da eliminação das diferenças e imposição de um modo único de verdade. 
Cada sujeito da comunidade escolar pôde construir uma resposta subjetiva mais ou menos saudável para lidar com esse estranho tão familiar. Por outro lado, a relação da criança com os pais também passou a ficar mais exposta para os profissionais da escola, havendo, novamente, uma quebra de privacidade nem sempre desejada.

O contato direto sem escansão temporal e sem filtro com as imperfeições e com os tropeços dos filhos no âmbito acadêmico toca os pais em um lugar sensível. Tal como Lacan explora no Seminário X (1962-1963/1999) sobre os diferentes tipos de manifestação de angústia no corpo, algumas crianças sintomatizam, outras fazem acting outs, outras (num viés apático) se evadem da situação de aprendizado e recusam o saber, como se fossem espectadores de sua experiência escolar. Há ainda as crianças tomadas por uma inibição paralisante diante da demanda parental e da alta expectativa de sucesso. A capacidade da criança de amar e de trabalhar, trazida por Freud e citada no início deste artigo, ganhou contornos complexos. A pandemia nos fez arrastar a escola para dentro da família, convocando a recircunscrição do espaço simbólico de cada um.

A proposta da Psicanálise é a de uma elaboração discursiva do mal-estar, tendo na escuta seu principal instrumento. Ao dar voz ao sujeito, convidando-o a falar, o psicólogo escolar o auxilia a construir algum saber sobre si que o faça sintomatizar menos, amando e trabalhando melhor. Algumas questões trazidas pelos pais foram a falta de engajamento e de autonomia dos filhos, a angústia com o excesso de proximidade na relação familiar, o afastamento dos vínculos sociais, a divisão entre o tempo de trabalho e o tempo para cuidado dos filhos e o excesso de uso da tecnologia. Muitas questões já se colocavam antes da pandemia, porém, com a reclusão, os pais podem enxergá-las mais de perto e exacerbadas.

Com a pandemia, a autonomia do aluno foi posta em xeque neste espaço escolar compartilhado. A dificuldade de autonomia dos filhos foi uma queixa recorrente no discurso parental. Ser autônomo,_segundo Dunker (2020) é ser capaz de responsabilizar-se pelos efeitos do que fazemos, dizemos ou deixamos de fazer. O relato de muitos pais é de que foram retirados de sua função parental exclusiva para exercerem também o papel de pedagogos dos próprios filhos. Nessa tentativa de incorporação de funções, alguns pais sentiram-se impelidos a acompanharem os filhos, cuidando pessoalmente de cada detalhe e, muitas vezes, realizando o trabalho no lugar da criança. Vale lembrar que, mesmo no EAD, o professor continua sendo o terceiro para a qual a criança deve responder, responsabilizando-se sobre suas tarefas. Algumas crianças conseguem estabelecer uma separação justamente recusando a invasão dos pais nesse novo espaço escolar, porém outras não, principalmente neste importante interstício que se dá entre o final do último semestre da Educação infantil e o início do Fundamental I. Percebo que, nesse movimento de autonomia, é preciso que os pais suportem esse processo de alienação e de separação dos filhos ${ }^{5}$.

\section{Pequenos lutos e atravessamentos}

Com a restrição de minha circulação na escola, a sinalização do mal-estar do aluno na pandemia iniciava-se pela escuta do professor, que, ao identificar algum tipo de mal-estar, me endereçava diretamente a questão. A partir daí, alguns caminhos puderam ser tomados. Os

5 Para Lacan, alienação e separação são operações fundantes do sujeito. Ele aborda a relação entre mãe e filho pelo viés dessas duas operações. O objeto a (objeto causa de desejo) é apontado por ele como possibilitador das operações de separação e de alienação. Alienamo-nos ao Outro como via de salvação, mas, ao mesmo tempo, precisamos dele nos separar e, assim, ver nosso próprio desejo advir. 
atendimentos se fazem por meio de uma plataforma online e não mais em minha sala na instituição. Há mudanças na forma de endereçamento da demanda, mas minha função como psicóloga escolar permanece a mesma. Instigar a curiosidade, fazer pensar, acolher equívocos, semear perguntas e encorajar o sujeito a atravessar, na medida do possível, situações de perda que se impõem a ele são funções do psicólogo escolar. Diante desse convite para iniciar um trabalho discursivo, pode-se operar uma transformação na forma como nos relacionamos conosco e com o outro.

Recordemos as reflexões que Freud (1916/1996, p.317) faz sobre a perenidade dos objetos desejados no texto Sobre a transitoriedade. Ainda que tudo que amamos e admiramos seja transitório, perene e mortal, isso não lhes rouba valor e beleza, pelo contrário. "O valor da transitoriedade é o valor da escassez no tempo". Como psicanalista e praticante escolar, penso que ainda é cedo para refletir sobre os efeitos da volta presencial à escola. Porém, ouso sonhar que a escassez temporária dessa experiência vivencial no espaço escolar tenha intensificado o desejo de pais e de crianças de partilhar com maior admiração desse lugar e das travessias que ali têm a oportunidade de construir. Como psicóloga escolar, disponho-me a acompanhar pais, educadores e crianças num trabalho de luto da escola presencial (e por que não da escola ideal?) ao confrontarem-se com a escola possível e distanciada. Leite (2020) lembra-nos de que a Educação deveria ser a mola propulsora de mudanças no mundo, um desafio constante ao código estabelecido e um campo que acolhe as diferenças para colocá-las em diálogo. Em outras palavras, o que experienciamos, no campo da Educação, durante a pandemia, deveria ser uma oportunidade de olharmos a partir de outros ângulos e sob nova ótica para a vida na escola, principalmente, no campo da Educação infantil.

Discordo da assertiva que já se tornou lugar-comum de que 2020 teria sido um "ano perdido". O que a pandemia nos ensinou é que a escola é muito mais do que um local de aprendizagem de disciplinas traduzidas como notas em um boletim. Se a escola é "lugar de vida", entendo que 2020 está sendo um ano repleto de oportunidades para reflexão e para criação a partir daquilo que o real da pandemia nos trouxe.

Como todo o sonhador, senti sempre que o meu mister era criar. Como nunca soube fazer um esforço ou activar uma intenção, criar coincidiu-me sempre com sonhar, querer ou desejar, e fazer gestos com sonhar os gestos que desejaria poder fazer. (Pessoa, 2006, p.297)

\section{Referências}

Aquino, J. G. (1996). A desordem na relação professor-aluno: indisciplina, moralidade e conhecimento. In J.G. Aquino (Org.), Indisciplina na escola: alternativas teóricas e práticas (pp.39-55). São Paulo: Summus.

Aquino, J. G. (1997). Confrontos na Sala de Aula: Uma leitura Institucional da relação professor-aluno. São Paulo: Summus.

Aquino, J. G. (1998). Ética na escola: a diferença que faz diferença. In J. G. Aquino (Coord.), Diferenças e preconceito na escola: alternativas teóricas e práticas (pp.135-151). São Paulo: Summus. 
Aquino, J. G. (1999). Autoridade e autonomia na escola: alternativas teóricas e práticas. São Paulo: Summus.

Austin, J. L. (1962). How to do things with words. London: Oxford University Press.

Bondía, J. L. (2002, jan./abr.). Notas sobre a experiência e o saber de experiencia. Revista Brasileira de Educação, 19, 20-28. doi: https://doi.org/10.1590/S141324782002000100003

Bimbati, A. P. (2000, Julho) Qual é a situação dos professores brasileiros durante a pandemia? Recuperado de https://novaescola.org.br/conteudo/19386/qual-e-a-situacao-dosprofessores-brasileiros-durante-a-pandemia.

Dunker, C. \& Thebas, C. (2019). O palhaço e o psicanalista. Como escutar os outros pode transformar vidas. São Paulo: Editora Planeta.

Dunker, C. (2020). A paixão da ignorância. A escuta entre a psicanálise e a educação. São Paulo: Editora Contracorrente.

Freud, S. (1996). Sobre o narcisismo: uma introdução. In S. Freud, Edição standard brasileira das obras psicológicas completas de Sigmund Freud (J. Salomão, trad., Vol. 14, pp. 77113). Rio Janeiro: Imago. (Trabalho original publicado em 1914).

Freud, S. (1996). Sobre a transitoriedade. In S. Freud, Edição standard brasileira das obras psicológicas completas de Sigmund Freud (J. Salomão, trad., Vol. 14, pp. 317-319). Rio Janeiro: Imago. (Trabalho original publicado em 1916).

Freud, S. (1996). O mal estar na civilização. In S. Freud, Edição standard brasileira das obras psicológicas completas de Sigmund Freud (J. Salomão, trad., Vol. 18, pp. 77-148). Rio Janeiro: Imago. (Trabalho original publicado em 1930).

Kupfer, M. C. M. (1982). Relação professor-aluno: Uma leitura psicanalítica. Dissertação de mestrado, Instituto de Psicologia, Universidade de São Paulo. São Paulo, 1982.

Kupfer, M. C. M. (1989). Freud e a educação: o mestre do impossível. São Paulo: Scipione.

Kupfer, M. C. M. (1999). Freud e a educação, dez anos depois. Boletim da Associação Psicanalítica de Porto Alegre, 9 (16), 14-26.

Kupfer, M. C. (2003) Leitura da constituição e da psicopatologia do laço social por meio de indicadores clínicos: uma abordagem multidisciplinar atravessada pela psicanálise. (Projeto de Pesquisa) São Paulo: USP/ IP, FAPESP.

Kupfer, M. C. M. \& Colli, F. A. G. (Orgs.). (2005). Travessias. Inclusão escolar: a experiência do Grupo Ponte Pré-escola Terapêutica Lugar de Vida-USP. São Paulo: Casa do Psicólogo.

Kupfer, M. C. M. (2010, jan./abr.). O sujeito na Psicanálise e na Educação: bases para a Educação terapêutica. Revista Educação e Realidade, 35(1), 265-282. https://seer.ufrgs.br/educacaoerealidade/article/view/9371/5412

Kupfer, M. C. M. \& Gaviolli, C. A. S. (2011). Médicos educadores e professores terapeutas? Algumas relações entre o tratar e o educar. In: Kupfer, M. C. M. \& Almeida, S. F. C. de. (Orgs.). A Psicanálise e o trabalho com a criança-sujeito: no avesso do especialista. Rio de Janeiro: Wak.

Kupfer, M. C. M. (2013). Educação para o futuro. Psicanálise e educação. São Paulo, Editora Escuta, 2013.

Lacan, J. (1999). O seminário, livro 5: As formações do inconsciente, 1957-1958. Rio de Janeiro, RJ: Zahar. 
Lacan, J. (2005). O seminário, livro 10: A angústia, 1962-1963. Rio de Janeiro, RJ: Zahar.

Lajonquière, L. (1998). A Psicanálise e o mal-estar escolar. Revista Espaço aberto, 8, 92-98.

Lajonquière, L. (2006). A Psicanálise e o debate sobre o desaparecimento da infância. Revista $\begin{array}{llll}\text { Educação } e & \text { realidade, } & \text { 89-105. }\end{array}$ https://seer.ufrgs.br/educacaoerealidade/article/view/22973/13258

Leite, M. I. (2020). Escolas e creches em tempos de pandemia. In C. Ruas \& M. I. Leite (Orgs), Precisamos priorizar as crianças (pp. 18-31). Editora: O Livreiro das Rosas.

Pessoa, F. (2006). Livro do desassossego. Organização de Richard Zenith. São Paulo: Companhia das Letras.

Voltolini, R. (2006). A educação como "fato inconveniente" para a psicanálise. Anais do $6^{\circ}$ Colóquio do LEPSI - Psicanálise, Educação e Transmissão, 6, São Paulo.Recuperado de http://www.proceedings.scielo.br/scielo.php?script=sci_arttext\&pid=MSC0000000032006 $\underline{000100006 \& \operatorname{lng}=\mathrm{en} \& \mathrm{nrm}=\mathrm{abn}}$

Voltolini, R. (2011). Educação e psicanálise. Rio de Janeiro: Zahar.

Rodrigues, R. J. (2020). Reflexiones sobre la pandemia. La educación, la imagicación creadora y el origem. In C. Ruas \& M. I. Leite (Orgs.), Precisamos priorizar as crianças (pp. 66-78). Editora: O Livreiro das Rosas.

Souza, C. A. (2014) Narrativas sobre o mal-estar escolar: psicólogo e professor coconstruindo entendimentos através de reuniões de trabalho. Anais da Jornada de Estudos da Linguagem, Rio de Janeiro, RJ, Brasil, 8.

Souza, C. A. (2015) Interseções entre a psicologia educacional, a prática exploratória e a sociolinguística interacional. A escola como espaço de construção de narrativas e elaboração psíquica. (Tese de Doutorado, Programa de Pós-Graduação em Estudos da Linguagem, Pontifícia Universidade Católica do Rio de Janeiro) Recuperado de https://www.maxwell.vrac.puc-rio.br/

Zizek, S. \& Daly G. (2006) Arriscar o impossível: conversas com Zizek. (V. Ribeiro, trad.), São Paulo: Martins Fontes.

Revisão gramatical: Talita Rosetti Souza Mendes

E-mail: talita.rosetti@gmail.com

Recebido em novembro de 2020 - Aceito em novembro de 2021. 